Title: Review of the Current State of Colorectal Cancer in Inflammatory Bowel Disease: What is the Real Risk and How Do We Manage It?

Deborah S Keller, MS MD, Division of Colon and Rectal Surgery, Department of Surgery, NewYork-Presbyterian, Columbia University Medical Center, New York, NY debby_keller@hotmail.com

Alistair Windsor, FRCS PhD, Consultant Colorectal Surgeon, Department of Surgery and Interventional Sciences, University College London Hospitals, NHS Foundation Trust, London, UK

Richard Cohen, FRCS MD, Consultant Colorectal Surgeon, Department of Surgery and Interventional Sciences, University College London Hospitals, NHS Foundation Trust, London, UK

Manish Chand, MBA FRCS PhD, GENIE Centre, University College London, London, UK

Word count: 4330

This paper has not been submitted to another journal, and has not been published in whole or in part elsewhere previously.

Conflict of Interest: DK, AW, RC, and MC declared no conflicts of interest The authors had no sources of funding for this work

Corresponding Author:

Deborah S Keller, MS MD

Assistant Professor of Surgery

Division of Colon and Rectal Surgery, Department of Surgery

NewYork-Presbyterian, Columbia University Medical Center

Herbert Irving Pavilion

161 Fort Washington Avenue, 8th Floor

New York, NY 10032

Phone: (646) 337-7184

E-mail: debby_keller@hotmail.com 


\begin{abstract}
$\underline{\text { Abstract }}$
Inflammatory bowel disease (IBD)-related colorectal cancer (CRC) is responsible for approximately $2 \%$ of the annual mortality from CRC overall, but $10 \%-15 \%$ of the annual deaths in IBD patients. IBD-related CRC patients are also affected at a younger age than sporadic CRC, and have a 5-year survival rate of 50\%. Despite optimal medical treatment, the chronic inflammatory state inherent in IBD increases the risk for highgrade dysplasia and $\mathrm{CRC}$, with additional input from genetic and environmental risk factors and the microbiome. Recognizing risk factors, implementing appropriate surveillance, and identifying high-risk patients is key to managing the CRC risk in IBD patients. Chemoprevention strategies exist, and studies evaluating their efficacy are underway. Once dysplasia or invasive cancer is diagnosed, appropriate surgical resection and post-operative treatment and surveillance are necessary. Here, we discuss the current state of IBD-related CRC, prevalence, risk factors, and evidence for surveillance, prophylaxis, and treatment recommendations.
\end{abstract}

Keywords: Inflammatory bowel disease, Crohn's disease, Ulcerative Colitis, Colorectal Cancer; Screening and Surveillance Colonoscopy; Chemoprophylaxis 


\section{Introduction and Current State}

Colorectal cancer (CRC) is the second most common cancer and cause of cancerassociated mortality in Europe [1]. Overall, a general trend of declining CRC-associated mortality is reported, from increased screening, earlier stage detection, and improved treatment options [2]. However this trend does not hold true for the Inflammatory Bowel Disease-related CRC (IBD-CRC) patient population, specifically Ulcerative Colitis (UC) and Crohn's disease (CD) patients.

The incidence and prevalence of IBD is increasing in worldwide, with approximately 2.5-3 million Europeans affected [3]. In the European Union, there are an estimated 176,000 new IBD cases annually (53,000 CD and 123,000 UC) [4]. Here, the prevalence of $\mathrm{CD}$ in Europe ranges from 1,522-2,1312 cases/100,000 persons, and the prevalence of UC varies from 2,422-2,946 cases/100,000 persons [5]. This incidence and prevalence is associated with an estimated direct healthcare cost of 4.6-5.6 billion Euros/year to care for the IBD population [3].

IBD patients are two-to-six times more prone to develop CRC than the general population [6, 7]. Furthermore, when cancer does develop, IBD-CRC patients are affected at a younger age than sporadic CRC patients. IBD-CRC patients are 7.7 years younger than non-IBD CRC patients at diagnosis, with a mean colitis-to-CRC interval of 16-21 years [8]. In 2001, Bernstein, et al. reported an increased IBD-CRC incidence rate for both CD $(2.64 ; 95 \%$ confidence interval $[95 \% \mathrm{CI}], 1.69-4.12)$ and $\mathrm{UC}(2.75 ; 95 \% \mathrm{CI}$, 1.91-3.97); there was an increased risk of rectal carcinoma only in UC (1.90; 95\% CI, 1.05-3.43) [9]. Other studies supported the overall increased CRC risk in UC, but with 
decreasing relative risk over time $[7,10,11]$. The risk in $\mathrm{CD}$ is more contentious. Studies reported the CRC relative risk 2.5-4.5-fold higher in CD than healthy subjects $[12,13]$. These values have changed over time, and a CD diagnosis may no longer significantly increase risk of CRC [14-16]. However, there are biases in the assessment of IBD-CRC, including its relatively low prevalence, the aging of the study cohorts, and the clinically heterogeneous nature of IBD, which can effect reported rates $[17,18]$. At any rate, $\mathrm{CRC}$ has a huge impact in this patient population. IBD-CRC is responsible for $10 \%-15 \%$ of the annual deaths in IBD patients, warranting further investigation [19].

\section{$\underline{\text { Risk Factors }}$}

Several known variables impact the risk of IBD-CRC. Age at diagnosis and disease duration are strong, independent risk factors [7, 20]. In general, CRC risk begins to increase 8-10 years after establishing the diagnosis, and increases over time. The incidence rates corresponded to cumulative probabilities for IBD-CRC of $2 \%$ by 10 years, $8 \%$ by 20 years, and $18 \%$ by 30 years [10]. The extent of mucosal inflammation and portion of the bowel affected are other risk factors [12]. Pancolitis patients are at higher risk, with prevalence of 5.7\% [10]. Patients with left-sided UC are also higher risk for IBD-CRC; however, patients with ulcerative proctitis have a CRC risk similar to that of the general population [21]. In CD, the relative risk of IBD-CRC is highest in patients with colonic disease and lowest in isolated ileal disease $[12,13,22]$. CD patients with penetrating disease and who had undergone immunosuppressive therapy are also at significantly higher IBD-CRC risk [23]. The presence of UC and concomitant primary sclerosing cholangitis (PSC) is also a risk. A study from the Swedish Cancer Registry 
found patients with an intact colon when diagnosed with PSC had a cumulative CRC risk of $16 \%$ after 10 years, while those with UC prior to diagnosis of PSC had a cumulative risk of $25 \%$ (24).

Geography plays a role in IBD-CRC development. The risk is higher in North America and the UK than in Scandinavian countries with no evidence of temporal impact [12]. In the US and UK, the annual risk of IBD-CRC is 4-5 cases/1000 person-years, whilst in Scandinavian and other countries it is 2 cases/1000 person-years [6]. The reason for geographic heterogeneity is multifactorial, including genetics, diet, chemoprevention, and variation in colonoscopic surveillance [6]. As with sporadic CRC, family history is associated with increased risk. IBD patients with CRC in a first-degree relative have twice the risk of developing CRC than those who do not [24]; patients with a first-degree relative diagnosed with $\mathrm{CRC}$ before 50 had a 9-fold higher relative risk [25]. Finally, a personal history of CRC and previous or synchronous colorectal adenomas are risk factors for IBD-CRC. The Gastrointestinal Oncology Group of the Spanish Gastroenterological Association reported patients with a personal history of CRC (odds ratio (OR), 5.58, 95\% CI, 1.01-31.01), and presence of previous or synchronous adenomas (OR, 1.77; 95 percent confidence interval, 1.21-3.17) have a significantly increased risk.

\section{The Molecular and Bacterial Basis for IBD-CRC}

Molecular alterations that occur in sporadic CRC, such as chromosomal instability, microsatellite instability and hypermethylation, play a role in IBD-CRC, but the order and frequency of these mutations, and the fact that they often occur before definite 
histologically-defined dysplasia, differentiates IBD-CRC from sporadic CRC [26] (Figure 1). The initiation and development of IBD-CRC is linked to inflammation, and follows a sequence of genetic alterations following an "inflammation-dysplasiacarcinoma" sequence, not the "adenoma-sequence" classically described in sporadic CRC $[27,28]$. The relationship between chronic inflammation and some molecular mediators that contribute to IBD-CRC are well established. Models highlight the role of toll-like receptors (TLR) and tumor necrosis factor- $\alpha$ (TNF- $\alpha$ ) in the activation of nuclear factor $\kappa \mathrm{B}(\mathrm{NF \kappa B})$ - a master regulator of inflammation, which then induces transcription of tumorigenesis genes, including COX-2 [29-31]. The inflammation induces apoptosis of intestinal epithelial cells via tumor suppressor p53 pathways; defective signaling via p53 may be an early event in the progression of dysplasia to cancer [32]. The p53 mutations occur earlier in IBD-CRC than sporadic CRC. These p53 mutations are also often in grossly normal nondysplastic mucosa, a contrast to sporadic CRC [6]. The development of a nonfunctional APC gatekeeper gene occurs later in IBD-CRC, just prior to carcinoma; this APC loss of function can occur because of chromosomal instability or MSI abnormalities, presenting in either polypoid or flat lesions [6]. IBD patients tend to have excessive inflammatory cell infiltration and expression of several inflammatory genes; this mucosal inflammation promotes cellular proliferation and ultimately CRC development [33]. With their increased presence in IBD-CRC compared to IBD without dysplasia, specific genetic mutations in KRAS and p53 could serve as biomarkers [34]. 
The dysbiosis of gut microbiota has an emerging role in IBD-CRC development [35, 36]. E. coli- a major contributor towards the induction of chronic inflammation during IBD and converting IBD into CRC- are dramatically increased in IBD. The lipopolysaccharides of the gram-negative bacteria increase expression of TLR4, a common event during IBD-CRC tumorigenesis [37]. E. coli also activates NF-kB expression, which plays a role in inducing inflammation and CRC development. Colibactin-equipped E. coli, an aggressive adherent invasive E. coli pathovar, are more prevalent in the colonic mucosa in Crohn's disease samples and, to a lesser extent, UC patients [38]. Other organisms overrepresented in the tumor microenvironment may act as pro-inflammatory factors, contributing to IBD-CRC, including Streptococcus bovis and Fusobacterium nucleatum [39]. The exact role of the microbiota dysbiotic component is continually evolving, and will be exciting to follow for therapeutic targets.

\section{Chemoprophylaxis}

Several agents have been evaluated for chemoprophylaxis, with varying impact. A systematic review and meta-analysis in average and high-risk CRC patients evaluated potential benefits of several prophylactic agents; IBD patients were not specifically evaluated, but the outcome can be applied in general [40]. For patients with adenomas or CRC history, there was a significant $21 \%$ reduction in adenoma recurrence and a $26 \%$ reduction in CRC incidence. In individuals with a history of adenomas, calcium (1200$2000 \mathrm{mg} /$ day) demonstrated a significant $18 \%$ reduction in the risk of adenoma recurrence. There was no significant effect with folic acid or antioxidants (vitamins A, C and E, beta carotene or selenium) on adenoma recurrence or incidence. Non-steroidal 
anti-inflammatory agents, such as Celecoxib (400 mg/day), had a significant 34\% reduction in adenoma recurrence and a $55 \%$ reduction in advanced adenoma incidence. In CRC survivors, NSAIDS are associated with a 3-fold decreased risk of recurrence and 7fold decreased risk of death [41].

$\mathrm{IBD}$ is a non-modifiable risk factor for $\mathrm{CRC}$; however, there is a role for chemoprophylaxis with pharmacological therapy to reduce the inflammation and causative organisms that increase risk of CRC [42]. Although it is accepted that chronic inflammation promotes colon cancer and chronic inflammation is the main cause of IBDCRC, the mechanisms involved are not clear [43]. Suppressing inflammation should lower the risk for IBD-CRC, but studies have not established that the anti-inflammatory agents most commonly used to treat IBD have chemopreventive effects against cancer. Effective anti-inflammatory chemoprophylactic agents are Sulfasalazine and the 5aminosalicylic acid (5-ASA) agents. Treatment with Sulfasalazine lasting at least 3 months was associated with a significant protective effect independent of disease activity [44]. A recent meta-analysis supported the chemopreventive effect of 5-aminosalicylic acid (5-ASA) agents in dosage $\geq 1.2 \mathrm{~g}$ /day in patients with IBD, with a significant additional effect in UC. The agents were effective only against CRC, not dysplasia [45]. Other work has shown mesalamine is associated with the risk reduction in the same dosage [46]. Anti-TNF agents induce and maintain mucosal healing in moderate-tosevere IBD and, as a result, are likely providing chemopreventative benefits by reducing long-standing chronic inflammation [47]. TNF-alpha has been reported to promote inflammation and IBD-CRC by promoting DNA damage, stimulating angiogenesis, and 
inducing expression of $\mathrm{COX}-2$, which also induces angiogenesis to promote tumor growth. In murine models, TNF- $\alpha$ expression was associated with the development of colonic tumors, while TNF-R blockade reduced inflammation and tumor development [48]; the effect was specifically seen with mice given the anti-TNF agents infliximab and etanercept [48, 49]. Although early investigations into the molecular mechanisms of TNF-alpha in IBD have suggested a possible direct antineoplastic role from TNF blockade, studies to date in human have not established that these agent prevent colon neoplasia[47].

An emerging prophylactic agent in preventing carcinogenesis is probiotic bacteria. Mouse models of colorectal cancer have shown producing conjugated linoleic acid activates PPAR $\gamma$, which inhibits COX-2 and induces apoptosis [50]. Further study is needed to validate this in human IBD-CRC.

\section{Screening and Surveillance Guidelines}

The aim of surveillance is to detect early dysplasia, and colonoscopy remains the gold standard in diagnosing intraepithelial neoplasia, dysplasia, or cancer in IBD [51]. Screening and surveillance is key to early detection, treatment, and prevention of CRC, but no randomized controlled studies have shown a reduced risk of CRC development by surveillance colonoscopy in IBD patients. While the association between IBD and CRC is well established, there are still concerns regarding timely diagnosis and treatment of early neoplastic lesions. Dysplastic lesions in IBD may occur as flat or raised mucosal lesions, and are differentiated by the terms dysplasia-associated lesion or mass (DALM)macroscopically flat or raised lesions without proper delineation to the surrounding 
mucosa- and adenoma-like mass (ALM)- sporadic adenomas that are similar to those observed in non-IBD patients (Figure 2, Table 1). IBD-CRC does not follow the classic adenoma-sequence; the rates the mucosa progresses to dysplasia is believed to be more rapid than the progression of adenomas to $\mathrm{CRC}$ in the non-IBD population [21].

Guidelines from the European Crohn's and Colitis Organization (ECCO), the American Gastroenterological Association (AGA), the British Society of Gastroenterology (BSG) and the Association of Coloproctology for Great Britain and Ireland (ACPGBI) agree that IBD patients are "High Risk" CRC, and surveillance colonoscopies should be started 8 years after the onset of pancolitis or 12-15 years after onset of left-sided and CD colitis, to assess disease extent and other endoscopic risk factors. However, there are discrepancies across guideline recommendations on the interval time between routine studies [52-54]. Colonoscopy surveillance is recommended to reassess disease extent every 1-2 years with biopsies for dysplasia [53, 54]. During surveillance, 2-4 random biopsies should be taken every $10 \mathrm{~cm}$ along the entire colon, with additional samples in suspicious areas, and 4-quadrant biopsy every $5 \mathrm{~cm}$ in the lower sigmoid and rectum. To aid detection, chromoendoscopy or pancolonic dye spraying with targeted biopsy of abnormal areas is recommended. If a dysplastic polyp is detected within an area of inflammation and can be removed in its entirety, colectomy is not necessary. Post colectomy, yearly flexible sigmoidoscopy of pouch/rectal mucosa in patients is recommended in higher risk patients- previous dysplasia or $\mathrm{CRC}$ at the time of pouch surgery, primary sclerosing cholangitis, mucosa exhibiting atrophy, or severe pouch inflammation. Lower risk post-colectomy patients can consider 5-yearly flexible 
sigmoidoscopy of the pouch/rectal mucosa if none of the aforementioned risk factors are present, taking four proximal and four distal pouch biopsies [55].

For the $1^{\text {st }}$ time, the BSG has recommended use of high-definition endoscopy chromoendoscopy or pancolonic dye spraying with targeted biopsy of abnormal areas [55]. This technique involves spraying a dye, such as indigo carmine or methylene blue, onto the mucosa to enhance visualization of subtle mucosal changes associated with dysplasia or neoplasia. With these tools, dysplasia, previously thought to be 'invisible' to the endoscopist, is now considered to be 'visible' [56]. This has implications for changing the paradigm of treating dysplastic lesions, where endoscopic resection can be considered, rather than radical surgery. Further studies are needed to determine its efficacy in this high-risk patient population, as well as if the additional training required offers a cost effective solution. Dye-based and magnification chromoendoscopy improve detection of dysplasia, and evaluation of inflammatory activity and extension of ulcerative colitis (Figure 3). Chromoendoscopy has proved highly effective and several guidelines suggest its use with a target biopsy [19]. Chromoendoscopy with confocal laser endomicroscopy (CLE) is reported to detect 4.75-fold more neoplasias than conventional colonoscopy, while requiring 50\% fewer biopsy specimens; it is not a technology for lesion detection alone, though [57]. This combination is most useful to identify areas of suspicion in IBD surveillance. However cost, availability, and experience are still an issue [58]. Dye-less chromoendoscopy modalities, including narrow band imaging, iScan, and autofluorescence imaging, can also enhance 
surveillance in comparison to white light endoscopy with optical or electronic filter technologies, but do not have the evidence to recommend routine use [59].

Whilst the current surveillance protocol is recommended for IBD patients, no randomized studies demonstrate a risk reduction in CRC development or mortality from surveillance colonoscopy, but indirect evidence suggests surveillance reduces the risk of death [60, 61]. There is evidence that cancer can generally be detected at an earlier stage with surveillance colonoscopy and that these patients have a better prognosis. Lutgens, et al. found the five-year survival rate after an IBD-CRC diagnosis was $100 \%$ in patients undergoing standard surveillance, compared to $74 \%$ in those not participating in surveillance, and more tumors were found at an early stage in the surveillance group [62]. A recent Cochrane review affirmed that endoscopic surveillance prolongs life by allowing earlier detection of CRC and dysplastic pre-cursor lesions in IBD [63]. The pooled analysis found the surveillance group had a significantly lower rate of CRC detection $(1.83 \%$ vs. $3.17 \%$, OR $0.58,95 \%$ CI 0.42 to $0.80 ; \mathrm{P}=0.0009)$, earlier stage CRC detection ( $16 \%$ vs. $8 \%$, OR 5.40, 95\% CI 1.51 to $19.30 ; \mathrm{P}=0.009)$, and a lower mortality ( $8 \%$ vs. $22 \%$, OR $0.36,95 \%$ CI 0.19 to $0.69, \mathrm{P}=0.002$ ), respectively [63].

Close clinical follow-up needs to be performed with IBD patients in addition to surveillance colonoscopy for cancer prevention. Issues of compliance with biopsy protocols and undersampling have been reported. In the United Kingdom, more than 50\% of the gastroenterologists surveyed obtained fewer than 10 colonic mucosal biopsies per examination [64]. In addition, while current guidelines recommend increased 
surveillance for $\mathrm{CRC}$ in this population, adherence remains poor and timing may not be adequate for detection. Much endoscopic surveillance is performed without following international recommended guidelines, rendering screening in this population ineffective $[65,66]$. A University of Minnesota study reported almost $1 / 2$ of their IBD-CRC patients had their cancer diagnosed because increased colitis symptoms led to colonoscopic examination outside of surveillance, and $18 \%$ of patients developed cancer with less than an eight-year history of IBD [67]. Another study from the Cancer Registry of Norway reported $21 \%$ of CRC in their registry study developed before 10 years of disease, which is before colonoscopic screening is usually recommended [68]. By relying solely on surveillance guidelines, these cancers could have been missed. Thus, further study should be focused on reassessing and increasing adherence to appropriate guidelines.

\section{$\underline{\text { Surgical Indications and Treatment Course }}$}

Recommendations for surgery are guided by screening and surveillance findings. Highgrade dysplasia (HGD), multifocal dysplasia, and invasive carcinoma are an absolute indication for surgery. DALM harbors a high-risk of progression to CRC, and is also a colectomy indication. There is over a $50 \%$ risk of developing cancer within 5 years of the diagnosis of dysplasia, and patients with DALM have a $20-30 \%$ risk of harboring an unrecognized synchronic or metachronic CRC [69-71]. Therefore, DALM patients are recommended to undergo prophylactic proctocolectomy with ileoanal pouch. Newer endoscopic excision techniques, such as en-bloc resection of the lesion with Endoscopic Submucosal Dissection or Endoscopic Mucosal Resection, have been described for resection of DALM and ALM when paired with chromoendoscopy and close surveillance. However, there is no long-term follow up of outcomes, controlled 
comparative studies to resection, and an experienced operator is necessary, so resection remains the best practice for DALM. In contrast, ALM patients can be treated with standard polypectomy and endoscopic surveillance with little risk of subsequent malignancy $[72,73]$. The need for complete excision in both lesions is stressed, as a high proportion of unresectable lesions harbored cancer [74] (Figure 4).

There is debate on the need for resection after low-grade dysplasia (LGD) is discovered. Both HGD and LGD are risk factors for IBD-CRC, with the likelihood of finding synchronous cancer at colectomy $42 \%$ with HGD and 19\% with LGD [52]. The variability in the risk of progression from LGD to HGD or cancer- ranging from 0-50\%leads to the management controversy $[75,76]$. Ullman, et al. reported a 53\% 5-year progression rate to HGD or CRC in UC patients with LGD discovered on surveillance colonoscopy [69]. Connell, et al. found similar 5-year progression rates of 54\% in longterm surveillance [75]. While there is proven advancement of LGD to DALMS, HGD, and frank cancer, the time to progression is unknown [76]. Thus, consideration of colectomy is valid with LGD. Wide variations in the perceptions and management of LGD in IBD were seen in a survey of British Society of Gastroenterology members [77]. $70 \%$ of respondents considered LGD premalignant, but only $13 \%$ offered routine colectomy, compared with $84 \%$ for HGD. Eighty-five percent considered LGD with DALM high-risk for concurrent CRC, but only 53\% offered total colectomy. Patients were more likely to be treated with colectomy for flat HGD (77\%) and HGD in the presence of DALM (86\%). Thus, there is a need for more research and consensus on LGD surgical recommendations. 
In addition, any patient unable or unwilling to undergo routine surveillance endoscopy should have surgery discussed to circumvent the risk of IBD-CRC. When the decision is made to go to surgery, a treatment course decided by the multidisciplinary team, including the surgeon, gastroenterologist, pathologist, oncologist, and the patient, is needed to optimize outcomes [78]. The goal of surgery in IBD-CRC is to remove all disease and tissue at risk with a complete oncological resection while preserving quality of life. The specific surgical plan varies by the diagnosis of UC or $\mathrm{CD}$, the lesion location, the patient's comorbidities, and personal wishes. IBD-CRC has greater propensity to develop in the proximal colon than sporadic CRC, and is significantly less likely to be located in the rectum compared to sporadic CRC [79]. The stage of cancer distribution is similar for IBD-CRC and sporadic CRC patients, but IBD-CRC tumors are often mucinous, and there is a higher frequency of multiple, synchronous tumors (OR 4.403, 95\% CI 2.32-8.36; $\mathrm{p}<0.001)$ and poor differentiation (OR $1.59-1.86,95 \%$ CI $1.26-$ $2.47 ; p<0.001)[6,67,79-81]$. With the rates of synchronous dysplasia and lesions, under ideal conditions, the surgical procedure of choice in IBD-CRC- both UC and CDis a total proctocolectomy (TPC) with ileal-pouch anal anastomosis (IPAA) [82]. These recommendations are consistent with population studies that demonstrate IBD-CRC patients- both UC and CD- were more likely to undergo total colectomy or total proctocolectomy than partial colectomy compared to non-IBD CRC patients [83]. In CD, segmental resection was formerly recommended, to spare bowel and fear of Crohn's disease of the pouch [84]. However, the diagnosis of adenocarcinoma is often not known at the time of resection, and a segmental resection would not guarantee appropriate 
oncological resection [78]. Furthermore, neoplasia in CD behaves similar to UC, supporting a more extensive UC-like surgical approach of total proctocolectomy with end ileostomy, instead of segmental resection, as the optimal course [85]. An IPAA is also an option for consideration in CD. IPAA procedures were historically discouraged in patients with known $\mathrm{CD}$ due to high rates of complications and subsequent pouch excision [86, 87]. There has been somewhat of a change in the management paradigm. While reported, $\mathrm{CD}$ of the pouch remains poorly defined and the diagnosis is often made on a non-specific clinical picture; actual pouch loss rates are low and functional results are favorable [88-90]. Thus, IPAA can be recommended in select cases of CD as an alternative to total protocolectomy with definitive end-ileostomy, with the patient well informed of the risks, failure rates, and functional results [87, 91]. Under less optimal conditions, including patient comorbidities, function, and personal preferences, lesser procedures may be made on an individual basis. These procedures for UC include a TPC with permanent ileostomy, subtotal colectomy with ileorectal anastomosis (IRA), segmental resection, and palliative procedures such as diverting colostomy or ileostomy (Figure 5). For a total abdominal colectomy with a stapled anastomosis, there are a few centimeters of colonic mucosa $(1-2 \mathrm{~cm})$ are left in situ below anastomosis, with a risk of malignant degeneration. The hand-sewn IPAA with mucosectomy reduces the risk of retained colonic mucosa below the anastomosis, but does not allow complete removal of columnar epithelium, which can progress to a malignant state [92]. This highlights the need for continued surveillance is needed after surgery.

\section{$\underline{\text { Postoperative Course and Prognosis }}$}


Postoperatively, IBD adversely impacts outcomes. A review of the National Inpatient Sample and Nationwide Readmissions Database showed IBD-CRC patients had longer length of stay, greater likelihood of postoperative complications, including wound infection and deep vein thrombosis, and were more likely to be readmitted within 30 days than sporadic CRC patients [83]. CD patients specifically were more likely to develop postoperative hemorrhage, hematoma or seroma, wound dehiscence, and poor wound healing [83].

Given the tumorigenetic and histomorphological differences between IBD-CRC and sporadic CRC, different treatment responses could be present. The current data supports the same indications for adjuvant chemotherapy. A morphologic similarity between IBDCRC and microsatellite instability high (MSI-H) CRC, with less response and higher risk of intestinal toxicity from fluorouracil-based chemotherapy was previously reported [93, 94]. However, the largest study to date comparing oncologic outcomes in IBD-CRC to sporadic CRCs found no significant differences, and supports fluorouracil-based chemotherapy is effective in IBD-CRC [95]. Patients with histologically active IBD also did not require chemotherapy alterations compared to inactive IBD patients [96]. Further prospective studies are needed to guide therapeutic decisions.

Long-term, IBD-CRC has higher recurrence and higher mortality rates than sporadic CRC $[67,80,97]$. A matched analysis reported local recurrence was three times higher $(\mathrm{p}=0.004)$ and 5-year survival significantly lower in IBD-CRC than sporadic CRC $(49 \%$ vs. $67 \%, p=0.03$ ) [97]. A meta-analysis of 3472 patients indicated IBD-CRC patients 
had shorter overall survival than sporadic CRC (HR 1.24, 95\% CI 1.19-1.29) [80]. A recent case-matched study supported IBD-CRC patients had a significantly shorter median overall survival than sporadic CRC (68.2 vs. 204.3 months, $\mathrm{P}=0.01)$; Stage 3 IBD-CRC patients specifically showed significantly decreased survival (23.0 vs. 133.9 months, $\mathrm{P}=0.008$ ). On multivariate analysis, after adjusting for $\mathrm{N}$ and $\mathrm{M}$ stage, IBD was associated with an increased risk of death compared to sporadic CRC $(\mathrm{HR}=2.011,95 \%$ CI 1.24-3.23, $\mathrm{P}=0.004$ ) [98]. Patients with stage IV IBD-CRC also had shorter survival than patients without IBD [96]. Thus, intensive surveillance and early treatment are essential [99]. More robust studies on long-term outcomes for IBD-CRC are needed. Recently, an international cross-disciplinary working group addressed this issue, and proposed a standardized set of patient-centered outcome measures for IBD, including domains of survival, colorectal cancer, and disease control [100]. This international template could facilitate better outcomes data in this population going forward.

There is a paucity of data on postoperative CD treatment after surgery for IBD-CRC. There is also no compelling evidence that anti-TNF therapy plays a role in solid tumor development. All IBD-CRC should be multidisciplinary management, with collaboration between gastroenterologists and oncologists, and must be based on the individual case, considering IBD activity, concomitant therapy, patient age, and the cancer type and stage [101]. 5-ASA agents and non-systemic steroids should be first line; thiopurines, calcineurin inhibitors, and anti-TNF agents should be stopped at least until cancer therapy is completed [101]. Preliminary data demonstrate no obvious risk of developing a new or 
recurrent cancer while being treated with anti-TNF therapy. Further research is needed on the topic for definitive recommendations.

\section{Conclusions}

The risk of developing CRC is increased in IBD, and affected patients have a worse outcome than sporadic CRC patients. The increased CRC risk in IBD is thought to be due to chronic inflammatory state, with new theories emerging on additional risk factors. Recognizing these factors, implementing appropriate surveillance, and identifying highrisk patients is key to managing the IBD-CRC. Several surveillance strategies are recommended to identify these lesions, and new endoscopic technology are emerging to identify the colitis-associated neoplasms more precisely than random biopsies. When dysplasia is discovered, surgery remains the most conservative option, with further evidence needed on the outcomes with endoscopic resection. After resection, evidencebased guidelines advise surveillance to manage the risk of recurrent dysplasia and CRC. Further study is needed on adjuvant treatment for CRC and CD treatment after surgery.

\section{Author Contributions:}

Dr. Keller: Substantial contribution to the conception, design of the work and consensus of topics; acquisition, synthesis, and interpretation of data for the work; drafting the work and revising it critically for important intellectual content; final approval of the version to be published; Agreement to be accountable for all aspects of the work in ensuring that questions related to the accuracy or integrity of any part of the work are appropriately investigated and resolved. 
Mr. Windsor- Substantial contribution to the conception, design of the work and consensus of topics; synthesis and interpretation of data for the work; revising the work critically for important intellectual content; final approval of the version to be published; Agreement to be accountable for all aspects of the work in ensuring that questions related to the accuracy or integrity of any part of the work are appropriately investigated and resolved.

Mr. Cohen- Substantial contribution to the conception, design of the work and consensus of topics; synthesis and interpretation of data for the work; revising the work critically for important intellectual content; final approval of the version to be published; Agreement to be accountable for all aspects of the work in ensuring that questions related to the accuracy or integrity of any part of the work are appropriately investigated and resolved. Mr. Chand- Substantial contribution to the conception, design of the work and consensus of topics; synthesis and interpretation of data for the work; revising the work critically for important intellectual content; final approval of the version to be published; Agreement to be accountable for all aspects of the work in ensuring that questions related to the accuracy or integrity of any part of the work are appropriately investigated and resolved. 


\section{Table Legend}

Table 1- Dysplastic lesions in Inflammatory Bowel Disease

Figure Legend

Figure 1- Pathways to progression to colorectal cancer in sporadic and inflammatory bowel disease associated colorectal cancer

Figure 2- DALM, Adenomatous lesions, and ALM comparison. A. Endoscopic view of a DALM under white light; B. Endoscopic view of a DALM with chromoendoscopy; C. Endoscopic view of an adenoma; D. Histology of an adenoma; E. Endoscopic view of an ALM; F. Histology of an ALM

Figure 3- Ulcerative Colitis colonoscopic view with white light and blue chromoemdoscopy dye

Figure 4- Rectal moderately differentiated adenocarcinoma in a Crohn's disease patient. Gross specimen, moderate, and high power histopathology views

Figure 5- Single Incision Laparoscopic Total Abdominal Colectomy with end ileostomy creation, as part of a staged total proctocolectomy procedure 
Conflict of Interest: None

References

1. Ferlay J, Soerjomataram I, Dikshit R et al. Cancer incidence and mortality worldwide: sources, methods and major patterns in GLOBOCAN 2012. Int J Cancer. 2015;136:E359-86.

2. Bradley CJ, Lansdorp-Vogelaar I, Yabroff KR et al. Productivity savings from colorectal cancer prevention and control strategies. Am J Prev Med. 2011;41:e5e14.

3. Burisch J, Jess T, Martinato M, Lakatos PL, ECCO E. The burden of inflammatory bowel disease in Europe. J Crohns Colitis. 2013;7:322-337.

4. Loftus EVJ. Clinical epidemiology of inflammatory bowel disease: Incidence, prevalence, and environmental influences. Gastroenterology. 2004;126:1504-1517.

5. Gheorghe C, Pascu O, Gheorghe L et al. Epidemiology of inflammatory bowel disease in adults who refer to gastroenterology care in Romania: a multicentre study. Eur J Gastroenterol Hepatol. 2004;16:1153-1159.

6. Mattar MC, Lough D, Pishvaian MJ, Charabaty A. Current management of inflammatory bowel disease and colorectal cancer. Gastrointest Cancer Res. 2011;4:53-61.

7. Ekbom A, Helmick C, Zack M, Adami HO. Ulcerative colitis and colorectal cancer. A population-based study. N Engl J Med. 1990;323:1228-1233.

8. Brackmann S, Andersen SN, Aamodt G et al. Two distinct groups of colorectal cancer in inflammatory bowel disease. Inflamm Bowel Dis. 2009;15:9-16.

9. Bernstein CN, Blanchard JF, Kliewer E, Wajda A. Cancer risk in patients with inflammatory bowel disease: a population-based study. Cancer. 2001;91:854-862.

10. Eaden JA, Abrams KR, Mayberry JF. The risk of colorectal cancer in ulcerative colitis: a meta-analysis. Gut. 2001;48:526-535.

11. Mellemkjaer L, Olsen JH, Frisch M, Johansen C, Gridley G, McLaughlin JK. Cancer in patients with ulcerative colitis. Int J Cancer. 1995;60:330-333.

12. von Roon AC, Reese G, Teare J, Constantinides V, Darzi AW, Tekkis PP. The risk of cancer in patients with Crohn's disease. Dis Colon Rectum. 2007;50:839-855.

13. Canavan C, Abrams KR, Mayberry J. Meta-analysis: colorectal and small bowel cancer risk in patients with Crohn's disease. Aliment Pharmacol Ther. 2006;23:1097-1104.

14. Jess T, Simonsen J, Jørgensen KT, Pedersen BV, Nielsen NM, Frisch M. Decreasing risk of colorectal cancer in patients with inflammatory bowel disease over 30 years. Gastroenterology. 2012;143:375-81.e1; quiz e13.

15. Jess T, Loftus EV, Velayos FS et al. Risk of intestinal cancer in inflammatory bowel disease: a population-based study from olmsted county, Minnesota. Gastroenterology. 2006;130:1039-1046.

16. Kappelman MD, Farkas DK, Long MD et al. Risk of cancer in patients with inflammatory bowel diseases: a nationwide population-based cohort study with 30 years of follow-up evaluation. Clin Gastroenterol Hepatol. 2014;12:265-73.e1.

17. Tsianos. Risk of cancer in inflammatory bowel disease (IBD). Eur J Intern Med. 2000;11:75-78. 
18. Lutgens MW, van Oijen MG, van der Heijden GJ, Vleggaar FP, Siersema PD, Oldenburg B. Declining risk of colorectal cancer in inflammatory bowel disease: an updated meta-analysis of population-based cohort studies. Inflamm Bowel Dis. 2013;19:789-799.

19. Fornaro R, Caratto M, Caratto E et al. Colorectal Cancer in Patients With Inflammatory Bowel Disease: The Need for a Real Surveillance Program. Clin Colorectal Cancer. 2016;15:204-212.

20. Rutter MD, Saunders BP, Wilkinson KH et al. Thirty-year analysis of a colonoscopic surveillance program for neoplasia in ulcerative colitis. Gastroenterology. 2006;130:1030-1038.

21. Ullman T, Odze R, Farraye FA. Diagnosis and management of dysplasia in patients with ulcerative colitis and Crohn's disease of the colon. Inflamm Bowel Dis. 2009;15:630-638.

22. van den Heuvel TR, Wintjens DS, Jeuring SF et al. Inflammatory bowel disease, cancer and medication: Cancer risk in the Dutch population-based IBDSL cohort. Int J Cancer. 2016;139:1270-1280.

23. Scaringi S, Di Martino C, Zambonin D et al. Colorectal cancer and Crohn's colitis: clinical implications from 313 surgical patients. World J Surg. 2013;37:902-910.

24. Nuako KW, Ahlquist DA, Mahoney DW, Schaid DJ, Siems DM, Lindor NM. Familial predisposition for colorectal cancer in chronic ulcerative colitis: a casecontrol study. Gastroenterology. 1998;115:1079-1083.

25. Askling J, Dickman PW, Karlén P et al. Family history as a risk factor for colorectal cancer in inflammatory bowel disease. Gastroenterology. 2001;120:13561362.

26. Sebastian S, Hernández V, Myrelid P et al. Colorectal cancer in inflammatory bowel disease: results of the 3rd ECCO pathogenesis scientific workshop (I). J Crohns Colitis. 2014;8:5-18.

27. Feagins LA, Souza RF, Spechler SJ. Carcinogenesis in IBD: potential targets for the prevention of colorectal cancer. Nat Rev Gastroenterol Hepatol. 2009;6:297-305.

28. Itzkowitz SH, Yio X. Inflammation and cancer IV. Colorectal cancer in inflammatory bowel disease: the role of inflammation. Am J Physiol Gastrointest Liver Physiol. 2004;287:G7-17.

29. Westbrook AM, Szakmary A, Schiestl RH. Mechanisms of intestinal inflammation and development of associated cancers: lessons learned from mouse models. Mutat Res. 2010;705:40-59.

30. Goel GA, Kandiel A, Achkar JP, Lashner B. Molecular pathways underlying IBDassociated colorectal neoplasia: therapeutic implications. Am J Gastroenterol. 2011;106:719-730.

31. McConnell BB, Yang VW. The Role of Inflammation in the Pathogenesis of Colorectal Cancer. Curr Colorectal Cancer Rep. 2009;5:69-74.

32. Dirisina R, Katzman RB, Goretsky $\mathrm{T}$ et al. p53 and PUMA independently regulate apoptosis of intestinal epithelial cells in patients and mice with colitis. Gastroenterology. 2011;141:1036-1045.

33. Velayos FS, Loftus EV, Jess T et al. Predictive and protective factors associated with colorectal cancer in ulcerative colitis: A case-control study. Gastroenterology. 2006;130:1941-1949. 
34. Bezzio C, Festa S, Saibeni S, Papi C. Chemoprevention of colorectal cancer in ulcerative colitis: digging deep in current evidence. Expert Rev Gastroenterol Hepatol. 2017;11:339-347.

35. Kang M, Martin A. Microbiome and colorectal cancer: Unraveling host-microbiota interactions in colitis-associated colorectal cancer development. Semin Immunol. 2017

36. Grivennikov SI. Inflammation and colorectal cancer: colitis-associated neoplasia. Semin Immunopathol. 2013;35:229-244.

37. McCoy AN, Araújo-Pérez F, Azcárate-Peril A, Yeh JJ, Sandler RS, Keku TO. Fusobacterium is associated with colorectal adenomas. PLoS One. 2013;8:e53653.

38. Arthur JC, Perez-Chanona E, Mühlbauer M et al. Intestinal inflammation targets cancer-inducing activity of the microbiota. Science. 2012;338:120-123.

39. Khan AA, Khan Z, Malik A et al. Colorectal cancer-inflammatory bowel disease nexus and felony of Escherichia coli. Life Sci. 2017

40. Cooper K, Squires H, Carroll C et al. Chemoprevention of colorectal cancer: systematic review and economic evaluation. Health Technol Assess. 2010;14:1-206.

41. Johnson CC, Jankowski M, Rolnick S, Yood MU, Alford SH. Influence of NSAID Use Among Colorectal Cancer Survivors on Cancer Outcomes. Am J Clin Oncol. 2014

42. Haggar FA, Boushey RP. Colorectal cancer epidemiology: incidence, mortality, survival, and risk factors. Clin Colon Rectal Surg. 2009;22:191-197.

43. Ullman TA, Itzkowitz SH. Intestinal inflammation and cancer. Gastroenterology. 2011;140:1807-1816.

44. Pinczowski D, Ekbom A, Baron J, Yuen J, Adami HO. Risk factors for colorectal cancer in patients with ulcerative colitis: a case-control study. Gastroenterology. 1994;107:117-120.

45. Qiu X, Ma J, Wang K, Zhang H. Chemopreventive effects of 5-aminosalicylic acid on inflammatory bowel disease-associated colorectal cancer and dysplasia: a systematic review with meta-analysis. Oncotarget. 2017;8:1031-1045.

46. O’Connor A, Packey CD, Akbari M, Moss AC. Mesalamine, but Not Sulfasalazine, Reduces the Risk of Colorectal Neoplasia in Patients with Inflammatory Bowel Disease: An Agent-specific Systematic Review and Meta-analysis. Inflamm Bowel Dis. 2015;21:2562-2569.

47. Chapman CG, Rubin DT. The potential for medical therapy to reduce the risk of colorectal cancer and optimize surveillance in inflammatory bowel disease.

Gastrointest Endosc Clin N Am. 2014;24:353-365.

48. Poutahidis T, Haigis KM, Rao VP et al. Rapid reversal of interleukin-6-dependent epithelial invasion in a mouse model of microbially induced colon carcinoma. Carcinogenesis. 2007;28:2614-2623.

49. Kim YJ, Hong KS, Chung JW, Kim JH, Hahm KB. Prevention of colitis-associated carcinogenesis with infliximab. Cancer Prev Res (Phila). 2010;3:1314-1333.

50. Bassaganya-Riera J, Viladomiu M, Pedragosa M, De Simone C, Hontecillas R. Immunoregulatory mechanisms underlying prevention of colitis-associated colorectal cancer by probiotic bacteria. PLoS One. 2012;7:e34676. 
51. Neumann H, Vieth M, Langner C, Neurath MF, Mudter J. Cancer risk in IBD: how to diagnose and how to manage DALM and ALM. World J Gastroenterol. 2011;17:3184-3191.

52. Guagnozzi D, Lucendo AJ. Colorectal cancer surveillance in patients with inflammatory bowel disease: What is new. World J Gastrointest Endosc. 2012;4:108-116.

53. Annese V, Daperno M, Rutter MD et al. European evidence based consensus for endoscopy in inflammatory bowel disease. J Crohns Colitis. 2013;7:982-1018.

54. Rex DK, Boland CR, Dominitz JA et al. Colorectal Cancer Screening: Recommendations for Physicians and Patients From the U.S. Multi-Society Task Force on Colorectal Cancer. Gastroenterology. 2017;153:307-323.

55. Cairns SR, Scholefield JH, Steele RJ et al. Guidelines for colorectal cancer screening and surveillance in moderate and high risk groups (update from 2002). Gut. 2010;59:666-689.

56. Abraham BP. Cancer surveillance in ulcerative colitis and Crohn's disease: new strategies. Curr Opin Gastroenterol. 2016;32:32-37.

57. Kiesslich R, Goetz M, Lammersdorf K et al. Chromoscopy-guided endomicroscopy increases the diagnostic yield of intraepithelial neoplasia in ulcerative colitis. Gastroenterology. 2007;132:874-882.

58. Gabbani T, Manetti N, Bonanomi AG, Annese AL, Annese V. New endoscopic imaging techniques in surveillance of inflammatory bowel disease. World $\mathbf{J}$ Gastrointest Endosc. 2015;7:230-236.

59. Cheon JH. Advances in the Endoscopic Assessment of Inflammatory Bowel Diseases: Cooperation between Endoscopic and Pathologic Evaluations. J Pathol Transl Med. 2015;49:209-217.

60. Lashner BA, Kane SV, Hanauer SB. Colon cancer surveillance in chronic ulcerative colitis: historical cohort study. Am J Gastroenterol. 1990;85:1083-1087.

61. Karlén P, Kornfeld D, Broström O, Löfberg R, Persson PG, Ekbom A. Is colonoscopic surveillance reducing colorectal cancer mortality in ulcerative colitis? A population based case control study. Gut. 1998;42:711-714.

62. Lutgens MW, Oldenburg B, Siersema PD et al. Colonoscopic surveillance improves survival after colorectal cancer diagnosis in inflammatory bowel disease. $\mathrm{Br} \mathrm{J}$ Cancer. 2009;101:1671-1675.

63. Bye WA, Nguyen TM, Parker CE, Jairath V, East JE. Strategies for detecting colon cancer in patients with inflammatory bowel disease. Cochrane Database Syst Rev. 2017;9:CD000279.

64. Eaden JA, Ward BA, Mayberry JF. How gastroenterologists screen for colonic cancer in ulcerative colitis: an analysis of performance. Gastrointest Endosc. 2000;51:123-128.

65. van Rijn AF, Fockens P, Siersema PD, Oldenburg B. Adherence to surveillance guidelines for dysplasia and colorectal carcinoma in ulcerative and Crohn's colitis patients in the Netherlands. World J Gastroenterol. 2009;15:226-230.

66. Feuerstein JD, Lewandowski JJ, Martinez-Vazquez M, Leffler DA, Cheifetz AS. Documented compliance with inflammatory bowel disease quality measures is poor. Dig Dis Sci. 2015;60:339-344. 
67. Mayer R, Wong WD, Rothenberger DA, Goldberg SM, Madoff RD. Colorectal cancer in inflammatory bowel disease: a continuing problem. Dis Colon Rectum. 1999;42:343-347.

68. Brackmann S, Andersen SN, Aamodt G et al. Relationship between clinical parameters and the colitis-colorectal cancer interval in a cohort of patients with colorectal cancer in inflammatory bowel disease. Scand J Gastroenterol. 2009;44:46-55.

69. Ullman TA. Patients with low-grade dysplasia should be advised to undergo colectomy. Inflamm Bowel Dis. 2003;9:267-9; discussion 273.

70. Bach JF. The effect of infections on susceptibility to autoimmune and allergic diseases. N Engl J Med. 2002;347:911-920.

71. DeRoche TC, Xiao SY, Liu X. Histological evaluation in ulcerative colitis. Gastroenterol Rep (Oxf). 2014;2:178-192.

72. Engelsgjerd M, Farraye FA, Odze RD. Polypectomy may be adequate treatment for adenoma-like dysplastic lesions in chronic ulcerative colitis. Gastroenterology. 1999;117:1288-94; discussion 1488.

73. Odze RD, Farraye FA, Hecht JL, Hornick JL. Long-term follow-up after polypectomy treatment for adenoma-like dysplastic lesions in ulcerative colitis. Clin Gastroenterol Hepatol. 2004;2:534-541.

74. Rutter MD, Saunders BP, Wilkinson KH, Kamm MA, Williams CB, Forbes A. Most dysplasia in ulcerative colitis is visible at colonoscopy. Gastrointest Endosc. 2004;60:334-339.

75. Connell WR, Lennard-Jones JE, Williams CB, Talbot IC, Price AB, Wilkinson KH. Factors affecting the outcome of endoscopic surveillance for cancer in ulcerative colitis. Gastroenterology. 1994;107:934-944.

76. Jess T, Loftus EV, Velayos FS et al. Incidence and prognosis of colorectal dysplasia in inflammatory bowel disease: a population-based study from Olmsted County, Minnesota. Inflamm Bowel Dis. 2006;12:669-676.

77. Thomas T, Nair P, Dronfield MW, Mayberry JF. Management of low and highgrade dysplasia in inflammatory bowel disease: the gastroenterologists' perspective and current practice in the United Kingdom. Eur J Gastroenterol Hepatol. 2005;17:1317-1324.

78. Althumairi AA, Lazarev MG, Gearhart SL. Inflammatory bowel disease associated neoplasia: A surgeon's perspective. World J Gastroenterol. 2016;22:961-973.

79. Reynolds IS, O'Toole A, Deasy J, McNamara DA, Burke JP. A meta-analysis of the clinicopathological characteristics and survival outcomes of inflammatory bowel disease associated colorectal cancer. Int J Colorectal Dis. 2017;32:443-451.

80. Ou B, Zhao J, Guan S, Lu A. Survival of Colorectal Cancer in Patients With or Without Inflammatory Bowel Disease: A Meta-Analysis. Dig Dis Sci. 2016;61:881889 .

81. Larsen M, Mose H, Gislum M et al. Survival after colorectal cancer in patients with Crohn's disease: A nationwide population-based Danish follow-up study. Am J Gastroenterol. 2007;102:163-167.

82. Panis Y. Is there a place for ileal pouch-anal anastomosis in patients with Crohn's colitis. Neth J Med. 1998;53:S47-51. 
83. Ramsey M, Krishna SG, Stanich PP et al. Inflammatory Bowel Disease Adversely Impacts Colorectal Cancer Surgery Short-term Outcomes and Health-Care Resource Utilization. Clin Transl Gastroenterol. 2017;8:e127.

84. Coviello LC, Stein SL. Surgical management of nonpolypoid colorectal lesions and strictures in colonic inflammatory bowel disease. Gastrointest Endosc Clin N Am. 2014;24:447-454.

85. Svrcek M, Cosnes J, Beaugerie L et al. Colorectal neoplasia in Crohn's colitis: a retrospective comparative study with ulcerative colitis. Histopathology. 2007;50:574-583.

86. Deutsch AA, McLeod RS, Cullen J, Cohen Z. Results of the pelvic-pouch procedure in patients with Crohn's disease. Dis Colon Rectum. 1991;34:475-477.

87. Keighley MR. The final diagnosis in pouch patients for presumed ulcerative colitis may change to Crohn's disease: patients should be warned of the consequences. Acta Chir Iugosl. 2000;47:27-31.

88. Melton GB, Fazio VW, Kiran RP et al. Long-term outcomes with ileal pouch-anal anastomosis and Crohn's disease: pouch retention and implications of delayed diagnosis. Ann Surg. 2008;248:608-616.

89. Tekkis PP, Heriot AG, Smith O, Smith JJ, Windsor AC, Nicholls RJ. Long-term outcomes of restorative proctocolectomy for Crohn's disease and indeterminate colitis. Colorectal Dis. 2005;7:218-223.

90. Lightner AL, Fletcher JG, Pemberton JH, Mathis KL, Raffals LE, Smyrk T. Crohn's Disease of the Pouch: A True Diagnosis or an Oversubscribed Diagnosis of Exclusion. Dis Colon Rectum. 2017;60:1201-1208.

91. Panis Y, Poupard B, Nemeth J, Lavergne A, Hautefeuille P, Valleur P. Ileal pouch/anal anastomosis for Crohn's disease. Lancet. 1996;347:854-857.

92. Gentilini L, Coscia M, Laureti S, Poggioli G. Surgery in presence of dysplasia in IBD. Ann Ital Chir. 2011;82:37-40.

93. Liu X, Goldblum JR, Zhao Z et al. Distinct clinicohistologic features of inflammatory bowel disease-associated colorectal adenocarcinoma: in comparison with sporadic microsatellite-stable and Lynch syndrome-related colorectal adenocarcinoma. Am J Surg Pathol. 2012;36:1228-1233.

94. Tiersten A, Saltz LB. Influence of inflammatory bowel disease on the ability of patients to tolerate systemic fluorouracil-based chemotherapy. J Clin Oncol. 1996;14:2043-2046.

95. Dugum M, Lin J, Lopez R et al. Recurrence and survival rates of inflammatory bowel disease-associated colorectal cancer following postoperative chemotherapy: a comparative study. Gastroenterol Rep (Oxf). 2017;5:57-61.

96. Axelrad J, Kriplani A, Ozbek U et al. Chemotherapy Tolerance and Oncologic Outcomes in Patients With Colorectal Cancer With and Without Inflammatory Bowel Disease. Clin Colorectal Cancer. 2017;16:e205-e210.

97. Renz BW, Thasler WE, Preissler G et al. Clinical outcome of IBD-associated versus sporadic colorectal cancer: a matched-pair analysis. J Gastrointest Surg. 2013;17:981-990.

98. Hrabe JE, Byrn JC, Button AM, Zamba GK, Kapadia MR, Mezhir JJ. A matched case-control study of IBD-associated colorectal cancer: IBD portends worse outcome. J Surg Oncol. 2014;109:117-121. 
99. Kim BJ, Yang SK, Kim JS et al. Trends of ulcerative colitis-associated colorectal cancer in Korea: A KASID study. J Gastroenterol Hepatol. 2009;24:667-671.

100. Kim AH, Roberts C, Feagan BG et al. Developing a Standard Set of PatientCentred Outcomes for Inflammatory Bowel Disease - an International, Crossdisciplinary Consensus. J Crohns Colitis. 2017

101. Annese V, Beaugerie L, Egan L et al. European Evidence-based Consensus: Inflammatory Bowel Disease and Malignancies. J Crohns Colitis. 2015;9:945-965. 
Table 1- Dysplastic lesions in Inflammatory Bowel Disease

\begin{tabular}{|l|l|l|l|l|}
\hline Type & Inflammation & $\begin{array}{l}\text { Macroscopic } \\
\text { View }\end{array}$ & Neighboring Tissue & Treatment \\
\hline $\begin{array}{l}\text { Dysplasia- } \\
\text { associated } \\
\text { lesion or mass } \\
\text { (DALM) }\end{array}$ & $\begin{array}{l}\text { In an area of } \\
\text { inflammation }\end{array}$ & $\begin{array}{l}\text { Single or } \\
\text { multiple } \\
\text { polyps, plaques } \\
\text { or velvety } \\
\text { patches, }\end{array}$ & $\begin{array}{l}\text { Surrounded by flat } \\
\text { dysplasia, } \\
\text { endoscopically } \\
\text { challenging to detect } \\
\text { amidst inflammation }\end{array}$ & $\begin{array}{l}\text { Surgical } \\
\text { resection }\end{array}$ \\
\hline $\begin{array}{l}\text { Adenoma-like } \\
\text { mass (ALM) }\end{array}$ & $\begin{array}{l}\text { Not in an } \\
\text { area of } \\
\text { inflammation }\end{array}$ & $\begin{array}{l}\text { Well } \\
\text { circumscribed } \\
\text { polyp, } \\
\text { amenable to } \\
\text { endoscopic } \\
\text { resection }\end{array}$ & $\begin{array}{l}\text { Not surrounded by flat } \\
\text { dysplasia, } \\
\text { endoscopically } \\
\text { indistinguishable from } \\
\text { a sporadic polyp }\end{array}$ & $\begin{array}{l}\text { Endoscopic } \\
\text { excision with } \\
\text { circumferential } \\
\text { biopsies to } \\
\text { rule out } \\
\text { neighboring } \\
\text { inflammation }\end{array}$ \\
\hline
\end{tabular}

